\title{
Procedure Agent Class
}

National Cancer Institute

\section{Source}

National Cancer Institute. Procedure Agent Class. NCI Thesaurus. Code C162121.

The variable assigned to a procedure agent class. 